\title{
Heteroduplex Mobility and Sequence Analyses for Assessment of Variability of Zucchini yellow mosaic virus
}

\author{
Shih-Shun Lin, Roger F. Hou, and Shyi-Dong Yeh
}

First and second authors: Graduate Institute of Agricultural Biotechnology; and third author: Department of Plant Pathology, National Chung Hsing University, Taichung, Taiwan 402, R.O.C.

Accepted for publication 15 November 1999.

\begin{abstract}
Lin, S. S., Hou, R. F., and Yeh, S. D. 2000. Heteroduplex mobility and sequence analyses for assessment of variability of Zucchini yellow mosaic virus. Phytopathology 90:228-235.

A heteroduplex mobility assay (HMA) was used to analyze the variability among five isolates of Zucchini yellow mosaic virus (ZYMV; TWTC1, TW-CY2, TW-TN3, TW-TNML1, and TW-NT1) collected from cucurbit fields in different areas of Taiwan. A cDNA fragment of $760 \mathrm{bp}$ covering the variable region of the $\mathrm{N}$ terminal half of the coat protein (CP) gene was amplified by reverse transcription-polymerase chain reaction (RT-PCR) and subsequently subjected to HMA analysis for sequence variation. When TW-NT1 combined with any of the other Taiwan isolates, the heteroduplexes obtained migrated much more slowly than did the heteroduplexes obtained in combinations among the other four Taiwan isolates, indicating that TW-TC1, TW-CY2, TW-TN3, and TW-TNML1 share a high degree of sequence homology, while the TW-NT1 isolate is more distinct. The complete nucleotide sequences of the CP genes and the $3^{\prime}$
\end{abstract}

ABSTRACT noncoding regions of the five isolates were determined from RT-PCRderived cDNA clones. A phylogenetic tree derived from the actual sequences of the 760-bp fragments of the five Taiwan and another six ZYMV isolates from different geographic areas revealed four genotypes. TW-TNML1, TW-TC1, TWC-Y2, and TW-TN3 were in genotype I, while TW-NT1 and U.S. isolates were in genotype II. The Singapore and Reunion Island isolates were separated into genotypes III and IV, respectively. Comparison of the $\mathrm{CP}$ genes of the five Taiwan isolates indicated that they share 92.8 to $98.7 \%$ nucleotide identities and 96.4 to 99.3\% amino acid identities. The amino acid positions 73, 102, 109, and 149 of the CP gene, where lysine, serine, arginine, and aspartic acid reside, respectively, were uniquely conserved for genotype I Taiwan isolates. Thus, results of HMA agreed well with those of phylogenetic analysis based on the sequence data of the five Taiwan ZYMV isolates. These five ZYMV isolates of known sequence can be used as reference strains for HMA to analyze the variability of ZYMV in Taiwan.
Zucchini yellow mosaic virus (ZYMV) causes one of the most destructive diseases of cucurbits worldwide (7). The disease is characterized by pronounced reduction in plant growth, yellow mosaic and distortion of leaves, and malformation of fruit $(28,33)$. Since the first report in Italy in 1981 (28), this disease has spread rapidly throughout Europe (23), the Middle East (25), the United States (1), and Taiwan (19). In Taiwan, the disease caused by ZYMV has been considered one of the major limiting factors for the production of cucurbits, followed in importance by Papaya ringspot virus type $\mathrm{W}$ (PRSV-W, formerly Watermelon mosaic virus-1 [WMV-1]) (34), Cucumber mosaic virus (CMV), and Melon veinbanding mosaic virus (20). Coat protein (CP)-mediated resistance as reported by Powell-Abel (32) has been successfully applied to a wide range of host-virus combinations, including several potyviruses $(6,14,27,30,41)$. Incorporation of transgenic resistance is considered an effective method for developing ZYMV-resistant cultivars. However, the resistance can be highly strain or isolate specific, with specificity probably determined by the relatedness of the transgene to the $\mathrm{CP}$ genes of the challenge viruses $(29,31,36,37)$. Therefore, the variability in amino acid or nucleotide sequences among the $\mathrm{CP}$ genes of the challenge viruses may have a significant effect on the level and stability of transgenic resistance.

Heteroduplex mobility assay (HMA), based on genetic differences between viral sequences, as applied to the analysis of ge-

Corresponding author: S. D. Yeh; E-mail address: sdyeh@nchu.edu.tw

The GenBank Accession numbers for the sequence data reported in this paper are AF127929 to AF127933.

Publication no. P-2000-0124-02R

(c) 2000 The American Phytopathological Society netic relationships of Human immunodeficiency virus (HIV) (11), has been shown to be a rapid, reliable, and cost-effective method for analysis of virus variability. Heteroduplexes are formed between polymerase chain reaction (PCR)-amplified fragments of variable regions of different isolates after denaturation and reannealing. The difference in migration of heteroduplexes in nondenaturing gel electrophoresis results from the effects of primary sequence changes forming mismatches, which cause bulges in doublestranded DNA fragments (12).

In our previous report, five ZYMV isolates (TW-TC1, TW-CY2, TW-TN3, TW-TNML1, and TW-NT1) were chosen as typical representatives from $33 \mathrm{ZYMV}$ isolates collected from cucurbit fields in different areas of Taiwan by host reactions, serology, and comparison of restriction patterns of the cDNAs that covered the variable region of the CP genes (26). In 1995, Thomson et al. distinguished the Australian ZYMV and WMV-2 by reverse transcription-polymerase chain reaction (RT-PCR) and investigated phylogenetic relationships of the published potyvirus (42). In this study, we analyze the variability among the $\mathrm{CP}$ genes of these five Taiwan ZYMV isolates by HMA. Also, phylogenetic relationships based on the actual nucleotide and amino acid sequences of the five Taiwan and six other isolates from different geographic areas were analyzed.

\section{MATERIALS AND METHODS}

Virus isolates and culture. The five Taiwan isolates of ZYMV consisted of TW-TC1, collected from pumpkin (Cucurbita maxima L.) in Taichung; TW-TN3, from sponge gourd (Luffa cylindrica Roem.) in Tainan; TW-CY2, from sponge gourd in Chiayi; TWNT1, from cucumber (Cucumis satvius L.) in Nanton; and TWTNML1, from melon (C. melo L. conomon group) in Tainan (26), 
and were maintained in zucchini squash (Cucurbita pepo L. var. zucchini) by mechanical inoculation. All test plants were kept in a temperature-controlled $\left(25\right.$ to $\left.30^{\circ} \mathrm{C}\right)$ greenhouse without light supplementation.

RT-PCR to amplify the variable region of the CP gene. Total RNA was isolated from leaves of zucchini squash infected with individual ZYMV isolates by the method of Verwoerd et al. (43) and Shrizadegan et al. (38) at 10 days after mechanical inoculation. The RT-PCR method of Bateson et al. (4) was used to amplify the variable region of the CP gene of ZYMV with some modifications. The published ZYMV sequences from GenBank were aligned to identify the conserved nucleotide sequences of the nuclear inclusion body protein $\mathrm{b}(\mathrm{NIb})$ and $\mathrm{CP}$ genes. Based on the conserved regions, the upstream primer ZNIb-2 (5'-GTGAACTGGCACGCTACC-3'), which was located at the C-terminal region of the $\mathrm{NIb}$ gene, and the downstream primer ZCP-2 (5'CAACAGCTTCGCGGG-3'), which was located at the C-terminal region of the $\mathrm{CP}$ gene, were used to amplify a DNA fragment with a predicted length of $760 \mathrm{bp}$, including the N-terminal variable region of the $\mathrm{CP}$ gene. Total RNA extracted from ZYMVinfected tissue was reverse-transcribed using Moloney murine leukemia virus reverse transcriptase (BRL, Gaithersburg, MD) with the downstream primer. The cDNA was then amplified by PCR using both downstream and upstream primers. PCR was performed with an initial cycle of $1 \mathrm{~min}$ of melting at $94^{\circ} \mathrm{C}, 2 \mathrm{~min}$ of annealing at $55^{\circ} \mathrm{C}$, and $2 \mathrm{~min}$ of synthesis at $72^{\circ} \mathrm{C}$, and followed by 33 cycles of $30 \mathrm{~s}$ of melting at $94^{\circ} \mathrm{C}, 2 \mathrm{~min}$ of annealing at $55^{\circ} \mathrm{C}$, and $2 \mathrm{~min}$ of synthesis at $72^{\circ} \mathrm{C}$, except synthesis at $72^{\circ} \mathrm{C}$ for the final cycle was $5 \mathrm{~min}$.

HMA. For formation of heteroduplexes, 4.5- $\mu$ l aliquots of PCR products from two virus isolates were combined, and $1 \mu \mathrm{l}$ of $10 \times$ annealing buffer (1M NaCl, $100 \mathrm{mM}$ Tris- $\mathrm{HCl}$ [pH 7.8], $20 \mathrm{mM}$ EDTA) was added. DNA was denatured at $94^{\circ} \mathrm{C}$ for $2 \mathrm{~min}$ and annealed by rapid cooling on ice. The heteroduplex products were separated in 5\% polyacrylamide gel in Tris-borate EDTA (TBE) buffer (0.088 M Tris-borate, 0.089 M boric acid, 0.002 M EDTA)

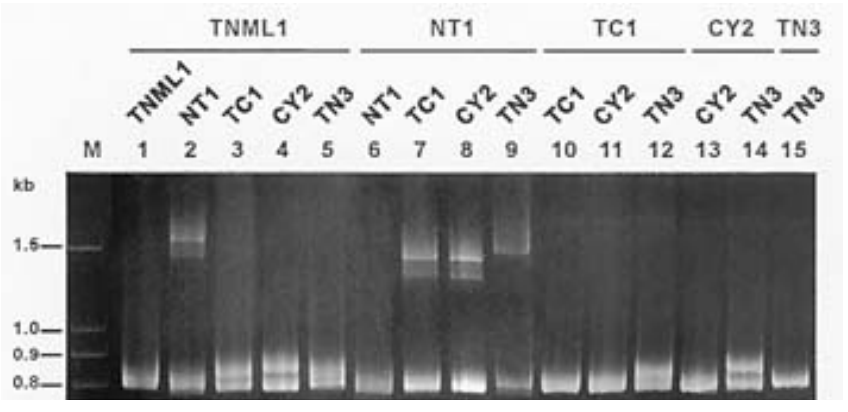

Fig. 1. Heteroduplex mobility assay of reverse transcriptase-polymerase chain reaction-amplified products, including the variable regions of the coat protein genes of five Taiwan Zucchini yellow mosaic virus isolates. The amplified 760-bp DNA fragments were denatured, reannealed, and separated in 5\% polyacrylamide gel.
TABLE 1. DNA distances deduced from heteroduplex mobilities and nucleotide sequences of 760-bp cDNA fragments that included the variable $\mathrm{N}$-terminal regions of the coat protein gene of Zucchini yellow mosaic virus (ZYMV) isolates from Taiwan

\begin{tabular}{lccccc}
\hline & \multicolumn{5}{c}{ Distance (\%) } \\
\cline { 2 - 6 } Isolate & TW-CY2 & TW-TC1 & TW-TN3 & TW-TNML1 & TW-NT1 \\
\hline TW-CY2 & $\ldots$ & $1.38(1.11)^{\mathrm{a}}$ & $1.90(2.53)$ & $2.00(2.97)$ & $7.39(9.02)$ \\
TW-TC1 & $0.99^{\mathrm{b}}$ & $\ldots$ & $1.68(2.25)$ & $1.83(2.68)$ & $7.36(8.69)$ \\
TW-TN3 & 0.93 & 0.95 & $\ldots$ & $1.70(2.40)$ & $9.14(8.54)$ \\
TW-TNML1 & 0.91 & 0.93 & 0.95 & $\ldots$ & $9.14(8.54)$ \\
TW-NT1 & 0.46 & 0.45 & 0.37 & 0.37 & $\ldots$ \\
\hline
\end{tabular}

${ }^{\mathrm{a}}$ DNA distance deduced from heteroduplex mobility by DNA distance $=$ $-\ln [($ mobility -0.045$) / 1.14] / 13.6$ (11). Numbers in parentheses indicate DNA distance calculated from nucleotide sequence using the DNADIST program in the PHYLIP software.

$\mathrm{b}$ Mobility of the average migration distance of the two heteroduplex bands divided by the mobility of the homoduplex band.
A

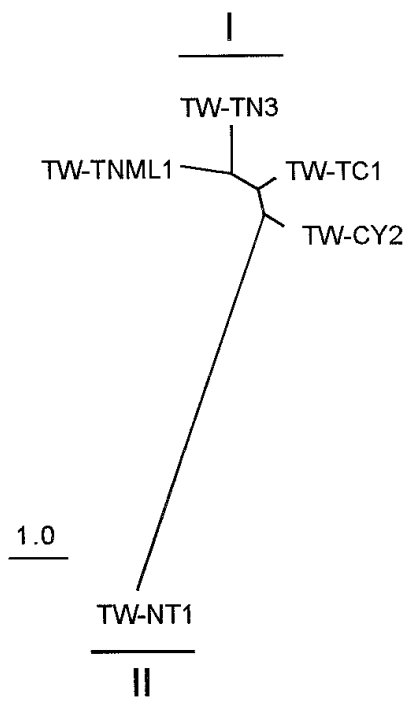

B

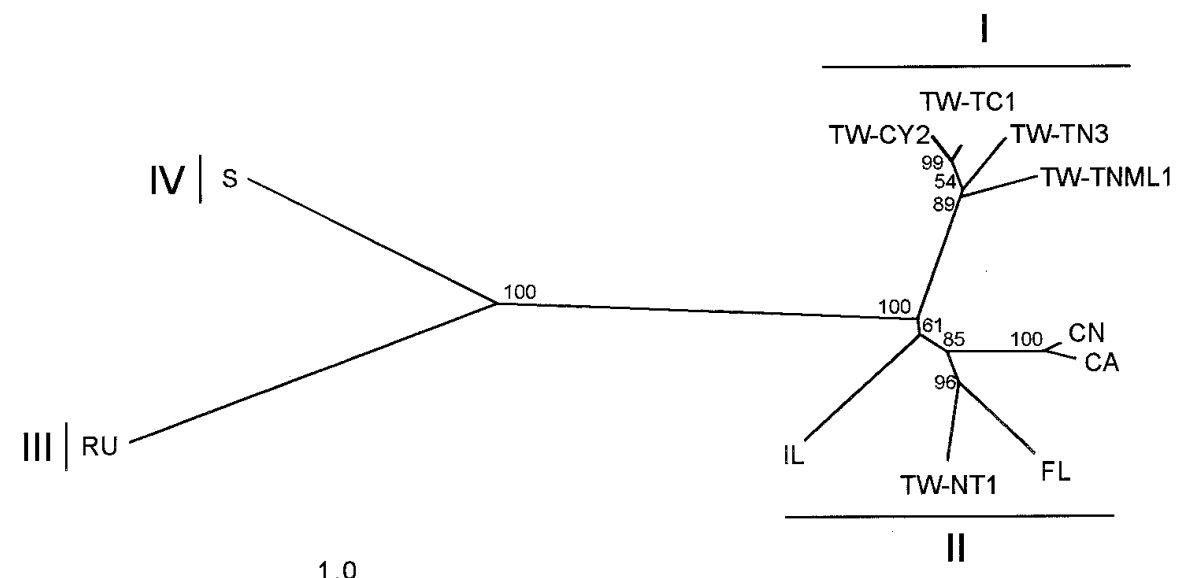

$\underline{1.0}$

Fig. 2. A, Phylogenetic tree based on DNA distances inferred from heteroduplex mobility assays of five Taiwan Zucchini yellow mosaic virus (ZYMV) isolates. The equation DNA distance $=-\ln [($ mobility -0.045$) / 1.14] / 13.6(11)$ was used to calculate the DNA distances based on heteroduplex mobility assays of the five ZYMV Taiwan isolates. A phylogenetic tree based on DNA distances was established using the PHYLIP software package (version $3.5 \mathrm{c}$ ). B, A phylogenetic tree based on DNA distances from actual nucleotide sequences of reverse transcriptase-polymerase chain reaction-amplified fragments. DNA distances were calculated from the actual nucleotide sequences of the 760-bp fragment, which included part of the nuclear inclusion body protein b gene and the $\mathrm{N}$-terminal half of the coat protein gene of 11 ZYMV isolates originating from Taiwan (TW-TC1, CY2, TN3, NT1, and TNML1), the United States (FL, CA, and CN), Singapore (S), Reunion Island (RU), and Israel (IL). The phylogenetic tree was established using the PHYLIP software package. Numbers indicating the percentage of 200 bootstrap replicates are shown at the appropriate nodes. The scale for genetic distances is indicated in the lower left quadrant of each panel. 
at $350 \mathrm{~V}$ for $1.5 \mathrm{~h}$ in a OWL P9DS vertical gel apparatus (OWL Scientific, Inc. Woburn, MA). Theoretically, there are two heteroduplex bands to be formed. The heteroduplex mobility was calculated as the average migration distance of the two heteroduplex bands divided by the migration distance of the homoduplex band. A distance equation, DNA distance $=-\ln [($ mobility -0.045$) / 1.14] / 13.6$, which was developed to estimate the genetic distance between HIV envelope genes by pairwise HMA (11), was used to predict the distances of variable regions of the CP genes of the five ZYMV isolates from Taiwan. To further analyze the phylogenetic relationships of the five isolates, DNA distances derived from HMA were used to establish an unrooted tree by the DRAWTREE and NEIGHBOR programs in the PHYLIP package (version 3.5c; Phylogeny Inference Package, University of Washington, Seattle).
Cloning and sequencing of the CP genes of ZYMV isolates. Because the 760-bp fragment only included the N-terminal half of the CP gene, an upstream primer TNP-1 (5'-GATCACAAAGAAGATGTCACTGCCA-3') and an oligo dT(18) downstream primer were used to amplify a DNA fragment of $870 \mathrm{bp}$ that covered the C-terminal half of the $\mathrm{CP}$ gene and the $3^{\prime}$ noncoding region (35). The RT-PCR procedure was similar to that for the 760-bp fragment. The 760- and 870-bp PCR products were cloned in the vector pCR 2.1 (Invitrogen, San Diego, CA) and sequenced using the Sequenase version 2.0 DNA sequencing kit (Amersham Life Science, Cleveland, OH) with M13 reverse and $\mathrm{T} 7$ primers.

Sequence analysis. Nucleotide sequences were assembled and amino acid sequences were predicted using PC/GENE 6.85 soft-

\section{$\mathrm{NIb} \leftrightarrow \rightarrow \mathrm{CP}$}

Consensus TACAAGCCCTCCATCAAGACATCTTCTTTGAACAAGGAGACACTGTAATGCTCCAATCAGGCACTCAGCCAACTGTGGCAGACGCTGGAGCTACAAAGAAAGACAAAGAAGATGACAAAG

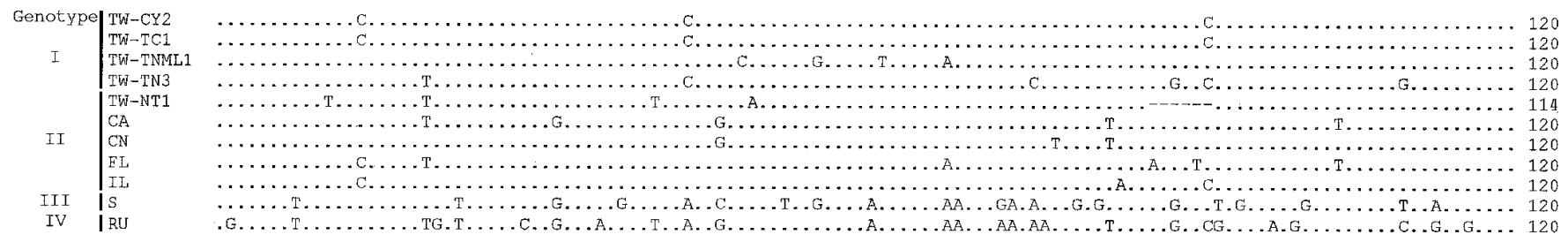

Consensus GGAAAAACAAGGATGTTACAGGCTCCGGCTCAGGTGAGAAAACAGTAGCAGCTGTCACGAAGGACAAGGATGTGAATGCTGGTTCTCATGGGAAATTGTGCCGCGTCTTTCGAAGATCA

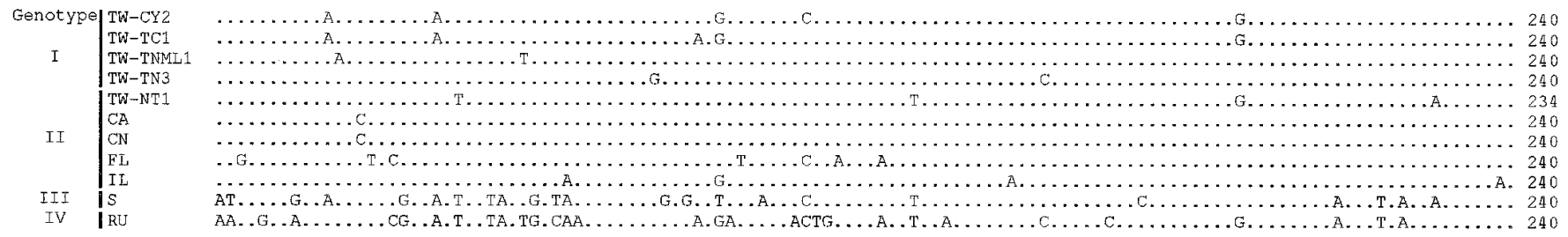

Consensus CAAAGAAGATGTCACTGCCACGCGTGAAAGGAAATGTGATACTCGATATCGATCATTTGCTGGAATATAAGCCGGATCAAATTGAGTTGTATAACACACGAGCGTCTCATCAGCAATTTG

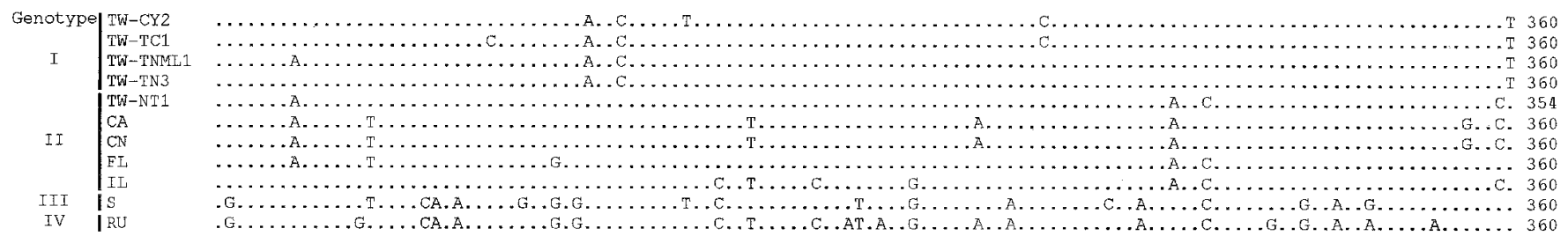

Consensus CCTCTTGGTTCAACCAAGTTAAACAGAATATGATTTGAATGAGCAACAGATGGGAGTTGTAATGAATGGTTTCATGGTTTGGTGCATTGAAAATGGCACTTCACCTGACATTAATGGAG

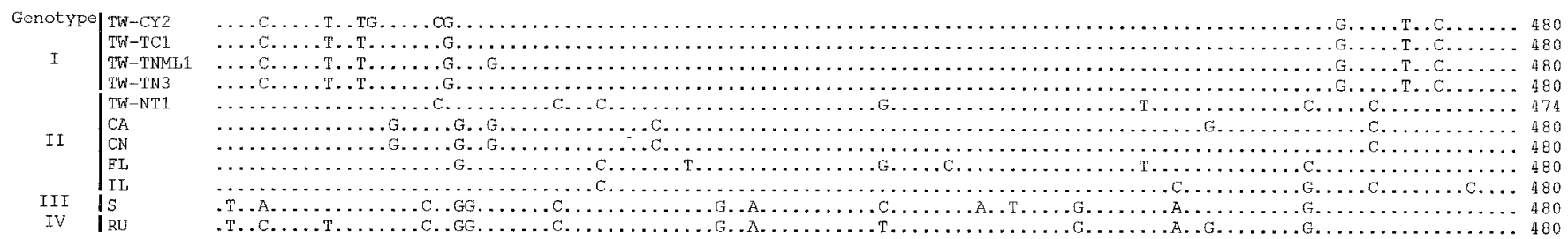

Consensus TGTGGTTTATGATGGACGGAAATGAGCAAGT TGAGTATCCTTTGAAACCAATAGTTGAAAATGCAAAGCCAACGCTGCGACAAATAATGCATCATTTCTCAGATGCAGCGGAGGCATATA

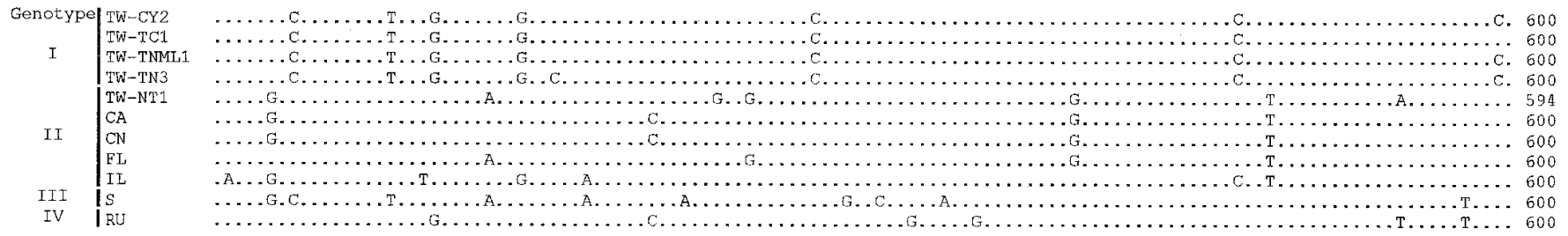

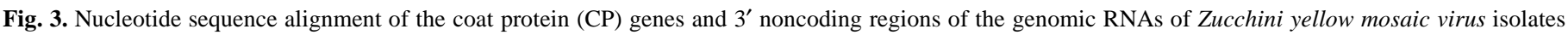

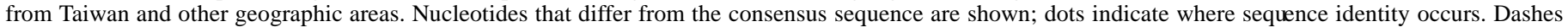
denote gaps in the sequence. The star indicates the termination codon of the CP gene. 
ware (IntelliGenetics, Inc., University of Geneva, Geneva, Switzerland). Multiple sequences were aligned by the PILEUP program in the GCG package (version 9.0, Genetics Computer Group, Madison, WI). Pairwise evolutionary distances for nucleotide sequences of the 760-bp fragments were estimated by using the DNADIST program of PHYLIP (version 3.5c) and using Kimura's two-parameter method (21) for superimposed-substitution corrections. Distance matrices for complete $\mathrm{CP}$ sequences were calculated from alignments based on the Dayhoff PAM matrix (8), using the program PROTDIST in PHYLIP. Phylogenetic relationships were established from these distances by using the Neighbor-Joining routines. The repeatability of the branching orders obtained was estimated using the SEQBOOT program for bootstrap resampling (200 bootstrap reiterations) of the multiple sequence alignment (13). Bootstrap consensus trees were built using the CONSENSE program. The Neighbor unrooted tree was drawn using the DRAWTREE program.

\section{RESULTS}

Heteroduplex mobility analysis. A DNA fragment of $760 \mathrm{bp}$ was amplified from the genomic region which covered the C-terminal 18 amino acids of the NIb gene and the N-terminal 227 amino acids of the CP gene by RT-PCR using primers ZNIb-2 and ZCP-2. When the heterologous DNA fragments were analyzed by HMA in a native $5 \%$ polyacrylamide gel, prominent bands that migrated more slowly were observed (Fig. 1) and considered heteroduplexes formed between divergent DNA molecules during the process of denaturing and reannealing. These heteroduplexes were not observed when the PCR products were reannealed in homologous combinations. When the 760-bp fragment of isolate TWTC1 was reannealed with that of isolate TW-CY2, the pattern was similar to that of the homologous control, indicating no significant sequence differences between the two isolates (Fig. 1, lanes 10

Fig. 3. (continued from preceding page)

Consensus TAGAGATGAGAATGCAGAGGCACCATACATGCCGAGGTATGGTTIGCTTCGAAATCTACGGGATAGGAGTTTAGCACGATACGCTTTCGACTTCTATGAAGTCAATTCTAAAACTCCTG

\begin{tabular}{c|l} 
Genotype & TW-CY2 \\
I & TW-TC1 \\
& TW-TNML1 \\
& TW-TN3 \\
& TW-NT1 \\
II & CA \\
& CN \\
& FL \\
II \\
III & S \\
IV & RU
\end{tabular}

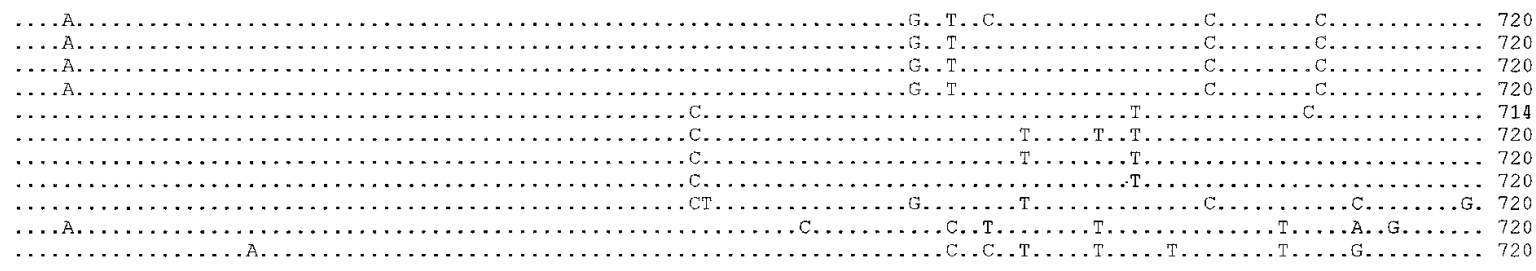

Consensus AAAGAGCCCGCGAAGCTGTTGCGCAGATGAAAGCAGCAGCTCT TAGCAATGTITCTTCAAGGTTGTTTGGCCTTGATGGAAATGTTGCCACCACTAGCGAAGACACTGAACGGCACACTG

\begin{tabular}{c|l} 
Genotype & TW-CY2 \\
I & TW-TC1 \\
& TW-TNML1 \\
TW-TN3 \\
II & TW-NT1 \\
CA \\
CN \\
& FL \\
III & IL \\
IV & I \\
IU
\end{tabular}

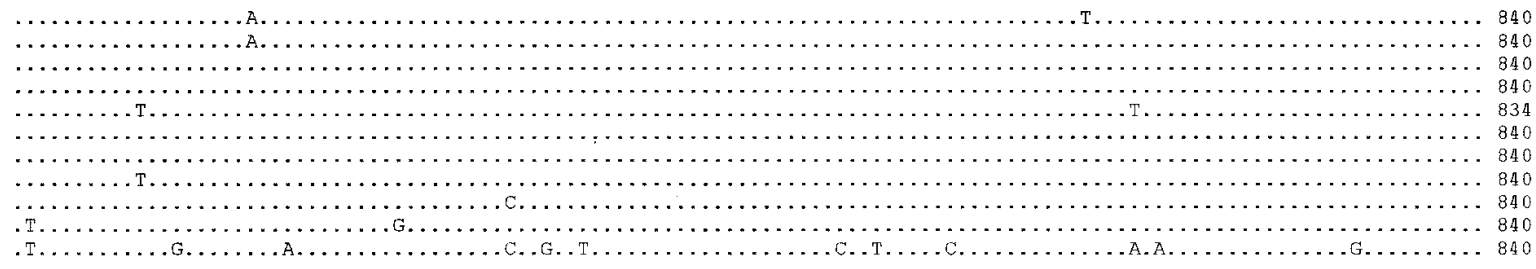

\section{$\mathrm{CP} \leftrightarrow \rightarrow 3^{\prime} \mathrm{NTR}$}

Consensus CACGTGATGTTAATAGAACATGCACACCTTACTAGGTGTGAATACAATGCAGTAAAGGGTAGGTCGCCTACCTAGGTTATCGATTCGCTGCCGACGTAATTCTAATATTTACCGCTTTA.

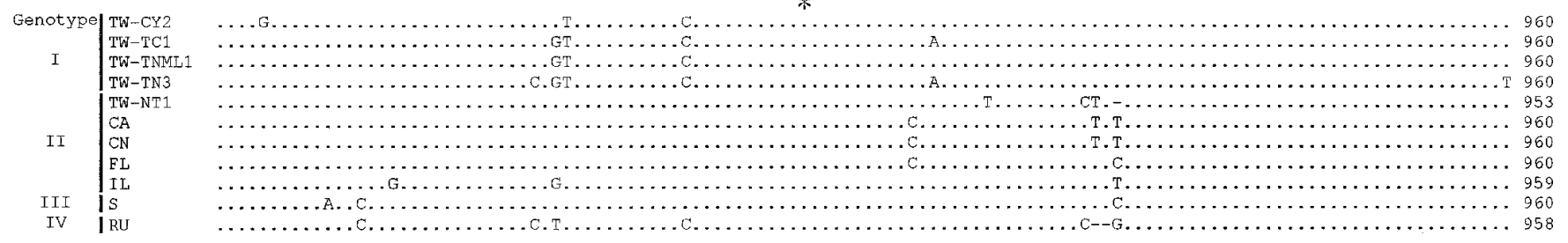

Consensus TTTGATATCT-------

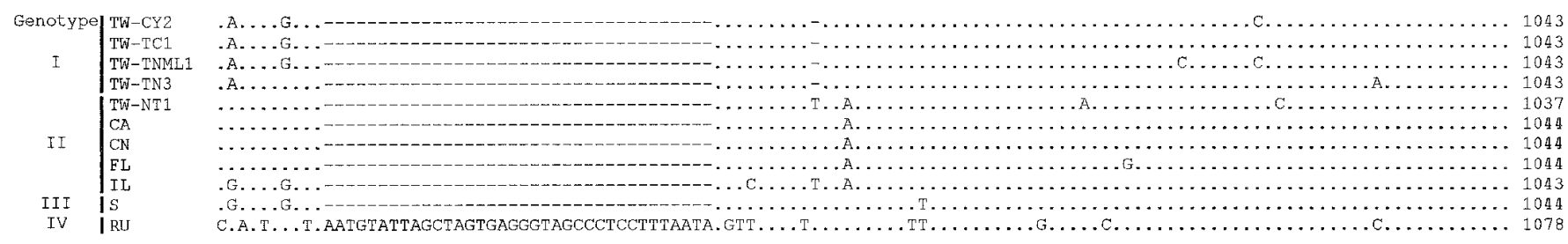

Consensus GTCGGAAGCTTIAGTGTGAGCCTCTCACGAATAAGCTCGAGATTAGACTCCGTTTGCAAGCCT

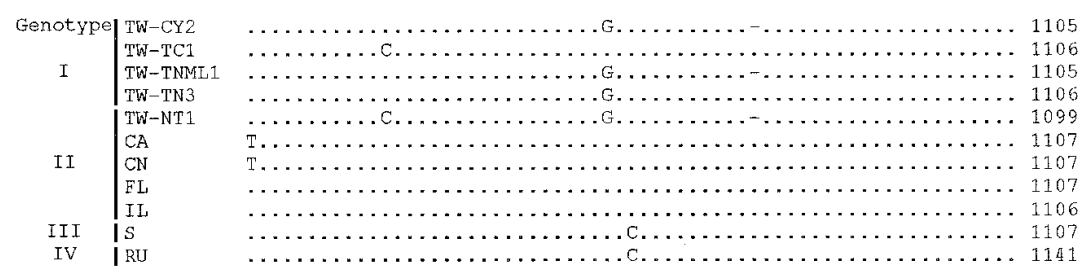


and 11). The slightly slower migration of heteroduplex bands for the heterologous combinations of TNML1-TC1, TNML1-CY2, TNML1-TN3, TC1-TN3, and CY2-TN3 indicated that they share a high degree of sequence homology with only slight sequence differences (Fig. 1, lanes 3, 4, 5, 12, and 14). On the contrary, much slower migration of heteroduplexes was observed in the TNML1NT1, NT1-TC1, NT1-CY2, and NT1-TN3 combinations (Fig. 1, lanes $2,7,8$, and 9), indicating that the TW-NT1 isolate shares a lesser degree of sequence homology with these isolates.

Phylogenetic relationships based on HMA. The DNA distances equation developed by Delwart (11) was used to estimate the genetic distances among the variable regions of the CP genes from the five ZYMV isolates examined by pairwise HMA. The heteroduplex mobilities and deduced DNA distances are summarized in Table 1. The heteroduplexes that were in the heterologous combinations TNML1-TC1, TNML1-CY2, TNML1-TN3, TC1-CY2, TC1TN3, and CY2-TN3 shared higher heteroduplex mobilities of 0.99 to 0.91 . However, when the TW-NT1 isolate was involved, the heteroduplexes had lower mobilities of 0.45 to 0.37 . The results showed that four isolates, TW-TNML1, TW-TC1, TWCY2, and TW-TN3, were closely related, because their DNA distances determined by HMA were only 1.38 to 2.00 , while TWNT1 was more distantly related to the other isolates, with deduced DNA distances of 7.36 to 9.14 . The phylogenetic tree based on deduced DNA distances also showed that four isolates, TWTNML1, TW-TC1, TW-CY2, and TW-TN3, could be classified in the same genotype, whereas the TW-NT1 isolate was distinct from them (Fig. 2A).

Phylogenetic relationships based on sequence analysis. The five 760-bp fragments of the ZYMV Taiwan isolates were cloned and sequenced, and the DNA distances calculated from the actual nucleotide sequences are summarized in Table 1. The distances among TW-CY2, TC1, TN3, and TNML1 showed little variation (1.11 to $2.97 \%$ ), while a wider variation of 8.54 to $9.02 \%$ was found between TW-NT1 and the other four isolates. The results indicated that TW-CY2, TC1, TN3, and TNML1 are closely related, whereas TW-NT1 is distinct.

A phylogenetic tree based on the nucleotide sequences of the 760-bp fragment amplified by RT-PCR was established by the distance matrix method and bootstrapping for 11 known sequences, including 5 Taiwan isolates (TC1, TN3, CY2, NT1, and TNML1), 3 U.S. isolates (FL, CA, and CN), 1 Israel isolate (IL), 1 Singapore isolate (S), and 1 Reunion Island isolate (RU) (Fig. 2B). The ZYMV isolates were placed in the same genotype if they had more than a $95 \%$ nucleotide identity. By this criterion, the virus isolates compared were grouped into four genetic types (genotypes I, II, III, and IV) (Fig. 2B). Four Taiwan ZYMV isolates (TW-TNML1, TW-TC1, TW-CY2, and TW-TN3) were in genotype I, while TWNT1, which resembled U.S. isolates, was placed in genotype II. The results agreed well with the prediction of the HMA phylogenetic tree (Fig. 2A).

Comparison of CP genes of Taiwan isolates with those of other isolates from different geographic areas. Nucleotide sequences of 1,099 to 1,106 bp were deduced from the RT-PCR-amplified Nterminal CP clones and the C-terminal CP clones for the five Taiwan isolates. This genomic region covered a part of the NIb protein (18 amino acids), the complete CP (277 to 279 amino acids), and the complete $3^{\prime}$ noncoding region (212 to $213 \mathrm{bp}$ ) (Fig. 3). The predicted amino acid translation of the nucleotide sequences of the five ZYMV isolates is shown in Figure 4. Of the 82 positions (9.7\% of the gene) at which nucleotide heterogeneity was found in the CP coding region, $75.6 \%$ were found in the third

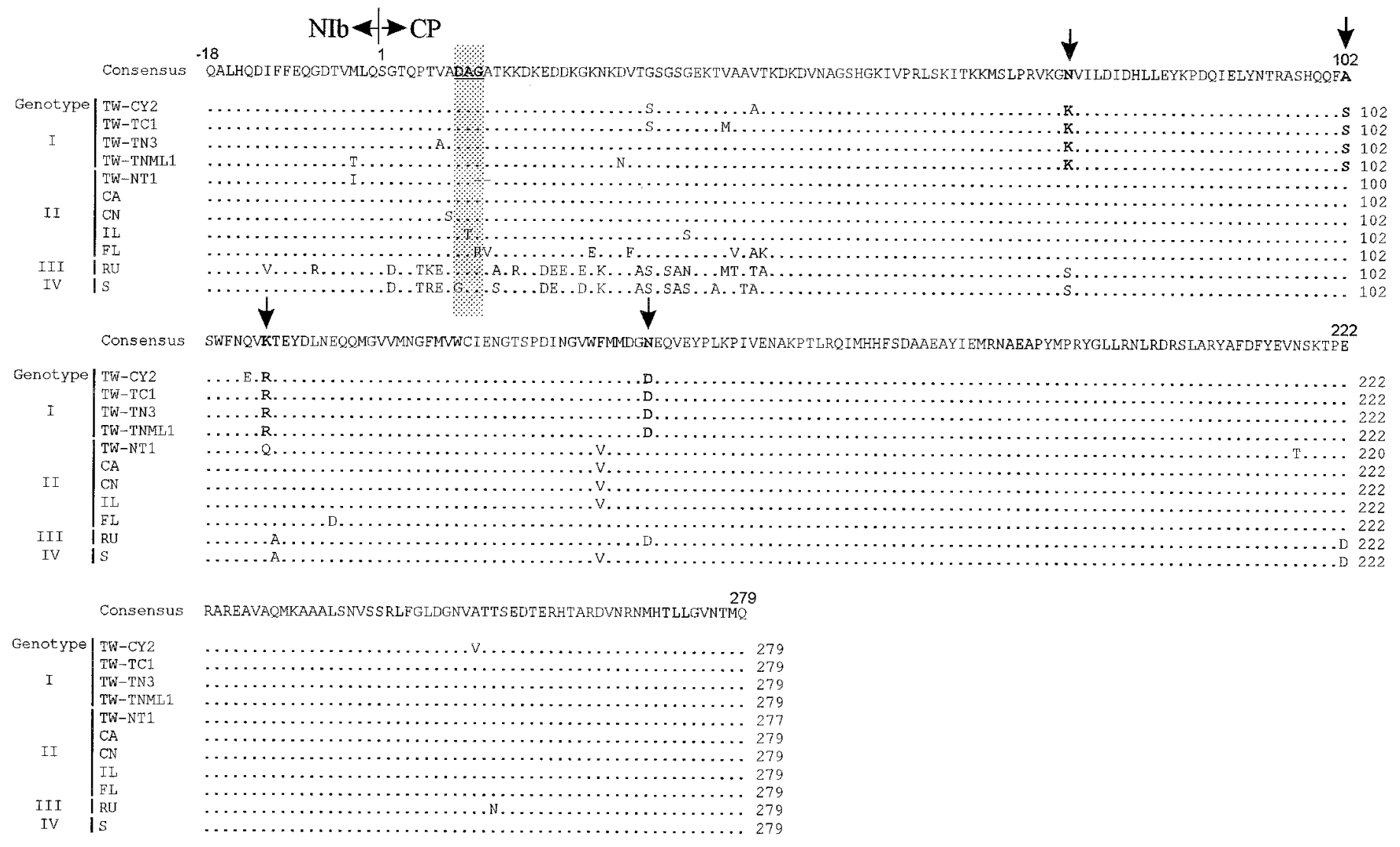

Fig. 4. Alignment of amino acid sequences of the coat protein coding regions of Zucchini yellow mosaic virus isolates from Taiwan and other geographic areas, as predicted based on the nucleotide sequences shown in Figure 3. Dots indicate where sequence identity occurs; dashes denote gaps in the sequence. Arrows denote positions where specific amino acids were conserved for specific genotypes. Box indicates the DAG motif for aphid transmission. Phylogenetic genotypes derived from the DNA distances shown in Figure 2B are indicated to the left. 
codon position and over $95.2 \%$ of these changes did not result in amino acid changes. At the protein level, $4.3 \%$ of the amino acid residues of the five isolates showed heterogeneity in the $\mathrm{CP}$ genes, and most of them were located in the N-terminal region of $\mathrm{CP}$ genes. Amino acid and nucleotide sequence alignments of this genomic region of the five ZYMV isolates from Taiwan and of the six other reported ZYMV isolates (CA, FL, S, IL, CN, and RU) $(15,18,24,35,45)$ are shown in Figures 3 and 4, respectively. Again, the N-terminal regions of the CP genes were more variable (Figs. 3 and 4). In addition, two amino acids of the TW-NT1 isolate were deleted (Gly and Ala) at positions 11 and 12 (Fig. 4).

Comparisons of the nucleotide and amino acid identities of the $\mathrm{CP}$ genes of the five ZYMV isolates from Taiwan with those of the reported ZYMV isolates are summarized in Table 2. The sequences of TW-TNML1, TW-TC1, TW-CY2, and TW-TN3 shared high nucleotide identities of 97.5 to $98.7 \%$. However, they had lower nucleotide identities of 84.4 to $94.2 \%$ with TW-NT1 and the other ZYMV isolates reported from the United States (FL, CN, and CA), Israel (IL), Singapore (S), and Reunion Island (RU). The amino acid identities among four Taiwan ZYMV isolates (TWTNML1, TW-TC1, TW-CY2, and TW-TN3) were 98.2 to $99.3 \%$, and they shared 90.3 to $97.9 \%$ amino acid identities with ZYMV isolates of other geographic origin (Table 2). Interestingly, TWNT1 had amino acid identities of 96.8 to $99.3 \%$ with U.S. and Israel isolates, while it had amino acid identities of 96.4 to $97.5 \%$ with other Taiwan isolates (Table 2). A phylogenetic tree of the amino acid sequences of the complete CPs of the ZYMV isolates, established by the neighbor-joining method, had four genetic genotypes similar to that derived from the RT-PCR-amplified 760-bp fragment (data not shown).

At certain amino acid positions in the $\mathrm{CP}$, there were amino acid residues specific for each genotype (Fig. 4): at position 73 in genotype I, it was lysine; in genotype II, it was asparagine; and in genotypes III and IV, it was serine. The alanine at position 102 in genotype II, III, and IV was replaced by a serine in genotype I. At position 109, the amino acid was arginine in genotype I and lysine in genotypes II, III, and IV, except that it was glutamine in TWNT1. At position 149, the amino acid residue was aspartic acid in genotypes I and III and asparagine in genotype II and IV.

\section{DISCUSSION}

HMA is particularly suitable for the analysis of rapidly evolving genetic systems such as RNA viruses. This technique has been used successfully for HIV subtype determination (11) and for quasispecies analysis of HIV (10) and Hepatitis C virus (44). For HMA analysis of the relationships of Taiwan isolates of ZYMV, the electrophoresis conditions and the distance equation created by Delwart et al. (11) were followed. The genetic types in the phylogenetic tree established by HMA (Fig. 2A) generally agreed well with those shown in the phylogenetic tree derived from comparison of the RT-PCR-amplified 760-bp fragment (Fig. 2B) and from complete amino acid sequences of the CPs of ZYMV isolates compared. Our results indicated that the distance equation adopted was able to reflect the relationships of the five ZYMV isolates analyzed.

Taxonomic analysis showed that TW-NT1 was consistently closest to the U.S. isolate, implying that TW-NT1 may have entered Taiwan from the United States. The phenomenon also was observed in Australian isolates of ZYMV (ZYMV-A3, G4, and K). The comparison of the 225 nucleotides from the C-terminal NIb and $\mathrm{N}$-terminal CP indicated they are more closely related to U.S. or Israeli isolates (42). Thomson et al.'s (42) results indicated that ZYMV may have entered Australia on more than one occasion.

The degree of nucleotide sequence variation required for discrimination of heteroduplexes has been shown to be within the range of 5 to $25 \%$ (9). Sequence divergence between TW-NT1 and other Taiwan isolates was 8.5 to $9 \%$. This was well reflected in the observation that the RT-PCR product of TW-NT1 forms prominent heteroduplex bands with those of other Taiwan isolates. The heteroduplex patterns separated the five Taiwan isolates into two groups (genotypes I and II). It, thus, is possible to use the HMA technique not only to differentiate the five ZYMV Taiwan isolates but also to identify other ZYMV isolates of interest that may have higher degrees of variation in the $\mathrm{CP}$ gene than the divergence among the five isolates. Moreover, the five sequenced ZYMV Taiwan isolates can be used as reference strains for comparing the heteroduplex patterns of unknown genotypes (5). Four ZYMV Taiwan isolates (TW-TNML1, TC1, CY2, and TN3) did not form clear heteroduplex bands among themselves. This apparently was due to the fact that their sequence divergences are less than 5\%. It may be possible to use a more sensitive technique for heteroduplex detection, such as electrophoresis on mutation detection enhancement gels (22). This system significantly improves resolution of configurationally different DNA molecules, permitting the detection of single-base substitutions, insertions, and deletions (5).

The estimated genetic distances derived from heteroduplex mobilities of five isolates were similar to those derived from the actual nucleotide sequences, except that the DNA distances of TW-NT1 with other isolates deduced from HMA were slightly different from those derived from actual nucleotide sequences (Table 1). This may be due to the fact that the six-nucleotide deletion in the CP of TW-NT1 causes the heteroduplexes to form a "bend" gap on the heteroduplexes. In contrast, the heteroduplexes of the other isolates were formed without gaps and the mismatches are thought to result in "bubbles" (12). The mobility of the heteroduplexes with putative bends or bubbles was different, so the estimated genetic distance values were slightly different from the distances derived from the actual nucleotide sequences in TW-NT1 pairing, resulting in a slight difference in arrangement within genotype I.

TABLE 2. Comparison of nucleotide and amino-acid identities of the coat protein coding regions of Zucchini yellow mosaic virus (ZYMV) isolates from Taiwan (TW) and other geographic areas ${ }^{\mathrm{a}}$

\begin{tabular}{|c|c|c|c|c|c|c|c|c|c|c|c|}
\hline & TW-CY2 & TW-TC1 & TW-TNML1 & TW-TN3 & TW-NT1 & $\mathrm{CA}$ & $\mathrm{CN}$ & FL & IL & $S$ & $\mathrm{RU}$ \\
\hline TW-CY2 & & 98.6 & 98.2 & 98.2 & 96.4 & 96.8 & 96.4 & 95.0 & 96.1 & 91.0 & 90.3 \\
\hline TW-TNML1 & 97.5 & 98.1 & & 99.3 & 97.5 & 97.9 & 97.5 & 95.3 & 97.1 & 90.7 & 90.3 \\
\hline TW-NT1 & 92.8 & 93.2 & 93.3 & 93.1 & 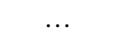 & 99.3 & 98.9 & 96.8 & 98.9 & 91.7 & 89.9 \\
\hline CA & 92.6 & 93.2 & 93.9 & 93.2 & 96.0 & $\ldots$ & 99.6 & 96.8 & 99.3 & 92.5 & 90.7 \\
\hline $\mathrm{CN}$ & 92.9 & 93.5 & 94.2 & 93.5 & 96.3 & 99.5 & $\ldots$ & 96.4 & 98.9 & 92.1 & 90.3 \\
\hline FL & 92.1 & 92.5 & 93.2 & 92.5 & 96.8 & 95.7 & 95.7 & $\ldots$ & 96.1 & 90.0 & 89.3 \\
\hline RU & 84.4 & 84.9 & 84.4 & 84.9 & 85.0 & 85.5 & 85.2 & 84.8 & 85.2 & 88.7 & $\ldots$ \\
\hline
\end{tabular}

${ }^{a}$ Percent identities are presented for the amino acid sequence (above the diagonal) and the nucleotide sequence (below the diagonal). The nucleotide sequences of ZYMV CA (California), CN (Connecticut), FL (Florida), IL (Israel), S (Singapore), and RU (Reunion Island) isolates were retrieved from the GenBank database (accession numbers L31350, D00692, D13914, M35095, X62662, and L29569, respectively). 
Nevertheless, sequence variation among Taiwan ZYMV isolates was resolved by HMA in this investigation, and virus isolates were grouped into distinct lineages which agreed with the actual DNA sequence analysis.

Comparison of $\mathrm{CP}$ sequence is widely accepted as a molecular basis for distinction of different potyvirus species, and it is generally accepted that amino acid identities among different potyvirus species range from 38 to $70 \%$, whereas they range from 90 to $99 \%$ for strains of the same potyvirus species $(39,40)$. The amino acid identities among the CPs of the five isolates from Taiwan are above the threshold of $90 \%$; thus, they are considered strains of ZYMV.

As in other potyviruses (40), the CP core of ZYMV is highly conserved, with most variable amino acids confined to the N-terminal region. Our results also indicated that the central and $\mathrm{C}$ terminal domains are conserved among isolates of ZYMV and the $\mathrm{N}$-terminal region is variable. The DAG triplet responsible for aphid transmission is located in the $\mathrm{N}$-terminal region of potyviral CPs $(2,3,16)$. The four ZYMV isolates from Taiwan (TW-TMNL1, TC1, CY2, and TN3) contained the DAG motif, but the TW-NT1 isolate was found with a deletion of two amino acids (Gly-Ala) at positions 11 and 12, and the DAG motif was replaced with DAT. Although a single amino acid change from DAG to GAG in the Singapore isolate or DAG to DTG in the Israel isolate resulted in loss of aphid transmissibility (24), TW-NT1 is as efficiently aphid transmissible as are the other four isolates (data not shown).

Sequence variability may have important implications in the use of the CP gene for transgenic resistance. Several lines of evidence from different virus-host systems suggest that such resistance can be highly sequence specific $(17,29,31,36,37)$. The HMA used in this study has proved to be a rapid and reliable tool for screening ZYMV isolates and will be useful for identifying the prevalent strain for further molecular studies and the development of transgenic resistance.

\section{ACKNOWLEDGMENTS}

This study was supported in part by the NSC grants (NSC 85-2621B005-011-B14 and 86-2313-B005-111-B14) of the Republic of China on Taiwan. We thank R.-J. Chiu for reviewing the manuscript.

\section{LITERATURE CITED}

1. Alderz, W. C., Purcifull, D. E., Simone, G. W., and Hiebert, E. 1983. Zucchini yellow mosaic virus: A pathogen of squash and other cucurbits in Florida. Proc. Fla. State Hortic. Soc. 96:72-74.

2. Atreya, C. D., Raccah, B., and Pirone, T. P. 1990. A point mutation in the coat protein abolishes aphid transmissibility of a potyvirus. Virology 178: 161-165.

3. Atreya, P. L., Atreya, C. D., and Pirone, T. P. 1991. Amino acid substitutions in the coat protein result in loss of insect transmissibility of a plant virus. Proc. Natl. Acad. Sci. USA 88:7887-7891.

4. Bateson, M. F., Henderson, J., Chaleeprom, W., Gibbs, A. J., and Dale, J. L. 1994. Papaya ringspot potyvirus: Isolate variability and the origin of PRSV type P (Australia). J. Gen. Virol. 75:3547-3553.

5. Chezzi, C., and Schoub, B. D. 1996. Differentiation between vaccinerelated and wild-type polioviruses using a heteroduplex mobility assay. J. Virol. Methods 62:93-102.

6. Da Camara Machado, M. L., Da Camara Machado, A., Hanzer, V., Weiss, H., Regner, F., Steinkellner, H., Mattanovich, D., Plail, R., Knapp, E., Kalthoff, B., and Katinger, H. 1992. Regeneration of transgenic plants of Prunus armeniaca containing the coat protein gene of plum pox virus. Plant Cell Rep. 11:25-29.

7. Davis, R. F. 1986. Partial characterization of zucchini yellow mosaic virus isolated from squash in Turkey. Plant Dis. 70:735-738.

8. Dayhoff, M. O., Barker, W. C., and Hunt, L. T. 1983. Establishing homologies in protein sequences. Methods Enzymol. 91:524-545.

9. Delwart, E. L., Herring, B., Rodrigo, A. G., and Mullins, J. I. 1995. Genetic subtyping of human immunodeficiency virus using a heteroduplex mobility assay. Manual supplement in: PCR Methods and Applications. Cold Spring Harbor Laboratory, Cold Spring Harbor, NY.

10. Delwart, E. L., Sheppard, H. W., Walker, B. D., Goudsmit, J., and Mullins, J. I. 1994. Human immunodeficiency virus type I evolution in vivo tracked by DNA heteroduplex mobility assays. J. Virol. 68:6672-6683.

11. Delwart, E. L., Shpaer, E. G., McCutchan, F. E., Louwagie, J., Grez, M., Rubsamen-Waigmann, H., and Mullins, J. I. 1993. Genetic relationships determined by a DNA heteroduplex mobility assay: Analysis of HIV-1 env genes. Science 262:1257-1261.

12. Delwart, E. L., Shpaer, E. G., and Mullins, J. I. 1995. Heteroduplex mobility assays for phylogenetic analysis. Page 154-160 in: PCR Strategies. Academic Press, San Diego, CA.

13. Felsenstein, J. 1985. Confidence limits on phylogenies: An approach using the bootstrap. Evolution 39:783-791.

14. Fitch, M. M. M., Manshardt, R. M., Gonsalves, D., Slightom, J. L., and Sanford, J. C. 1992. Virus-resistant papaya plants derived from tissues bombarded with the coat protein gene of papaya ringspot virus. Bio/Technology 10:1466-1472.

15. Gal-on, A., Antignus, Y., Rosner, A., and Raccah, B. 1990. Nucleotide sequence of the zucchini yellow mosaic virus capsid-encoding gene and its expression in Escherichia coli. Gene 87:273-277.

16. Gal-on, A., Antignus, Y., Rosner, A., and Raccah. B. 1992. A zucchini yellow mosaic virus coat protein gene mutation restores aphid transmissibility but has no effect on multiplication. J. Gen. Virol. 73:2183-2187.

17. Gonsalves, D. 1998. Control of papaya ringspot virus in papaya: A case study. Annu. Rev. Phytopathol. 36:415-437.

18. Grumet, R., and Fang, G. W. 1990. cDNA cloning and sequence analysis of the 3'-terminal region of zucchini yellow mosaic virus RNA. J. Gen. Virol. 71:1619-1622.

19. Hseu, S. H., Huang, C. H., Chang, C. A., Yang, W. Z., Chang, Y. M., and Hsiao, C. H. 1987. The occurrence of five viruses in six cucurbits in Taiwan. Plant Prot. Bull. 29:233-244.

20. Huang, C. H., Liang, S. C., Deng, T. C., and Hseu, S. H. 1993. Comparison of diagnostic hosts and serological tests for four cucurbit potyviruses. Plant Pathol. Bull. 2:169-176.

21. Kimura, M. 1980. A simple method for estimating evolutionary rates of base substitutions through comparative studies of nucleotide sequences. J. Mol. Evol. 16:111-120.

22. Kreis, S., and Whistler, T. 1997. Rapid identification of measles virus strains by the heteroduplex mobility assay. Virus Res. 47:197-203.

23. Lecoq, H., Lisa, V., and Dellavalle, G. 1983. Serological identity of muskmelon yellow stunt and zucchini yellow mosaic viruses. Plant Dis. 67:824-825.

24. Lee, S. C., Wu, M., and Wong, S. M. 1992. Nucleotide sequence of a Singapore isolate of zucchini yellow mosaic virus coat protein gene revealed an altered DAG motif. Virus Genes 7:381-387.

25. Lesemann, D.-E., Makkouk, K. M., Koenig, R., and Samman, E. N. 1983. Natural infection of cucumbers by zucchini yellow mosaic virus in Lebanon. Phytopathol. Z. 108:304-313.

26. Lin, S. S., Hou, R. F., Huang, C. H., and Yeh, S. D. 1998. Characterization of zucchini yellow mosaic virus (ZYMV) isolates collected from Taiwan by host reactions, serology, and RT-PCR. Plant Prot. Bull. 40:163-176.

27. Ling, K., Namba, S., Gonsalves, C., Slightom, J. L., and Gonsalves, D. 1991. Protection against detrimental effects of potyvirus infection in transgenic tobacco plants expressing the papaya ringspot virus coat protein gene. Bio/Technology 9:752-758.

28. Lisa, V., Boccardo, G., D'Agostino, G., Dellavalle, G., and D'Aquilio, M. 1981. Characterization of a potyvirus that causes zucchini yellow mosaic. Phytopathology 71:667-672.

29. Nakajima, M., Hayakawa, T., Nakamura, I., and Suzuki, M. 1993. Protection against cucumber mosaic virus (CMV) strain $\mathrm{O}$ and $\mathrm{Y}$ and chrysanthemum mild mottle virus in transgenic tobacco plants expressing CMV-O coat protein. J. Gen. Virol. 74:319-322.

30. Namba, S., Ling, K., Gonsalves, C., Slightom, J. L., and Gonsalves, D. 1992. Protection of transgenic plants expressing the coat protein gene of watermelon mosaic virus II or zucchini yellow mosaic virus against six potyviruses. Phytopathology 82:940-946.

31. Nelson, R. S., McCormick, S. M., Delannay, X., Dube, P., Layton, J., Anderson, E. J., Kaniewska, M., Proksch, R. K., Horsch, R. B., Rogers, S. G., Fraley, R. T., and Beachy, R. N. 1988. Virus tolerance, plant growth, and field performance of transgenic tomato plants expressing coat protein from tobacco mosaic virus. Bio/Technology 6:403-409.

32. Powell-Abel, P., Nelson, R. S., De, B., Hoffmann, N., Rogers, S. G., Fraley, R. T., and Beachy, R. N. 1986. Delay of disease development in transgenic plants that express the tobacco mosaic virus coat protein gene. Science 232:738-743.

33. Provvidenti, R., Gonsalves, D., and Humaydan, H. S. 1984. Occurrence of zucchini yellow mosaic virus in cucurbits from Connecticut, New York, Florida, and California. Plant Dis. 68:443-446.

34. Purcifull, D. E., Adlerz, W. C., Simone, G. W., Hiebert, E., and Christie, S. R. 1984. Serological relationships and partial characterization of zucchini yellow mosaic virus isolated from squash in Florida. Plant Dis. 68: 230-233. 
35. Quemada, H., Sieu, L. C., Siemieniak, D. R., Gonsalves, D., and Slightom, J. L. 1990. Watermelon mosaic virus II and zucchini yellow mosaic virus: Cloning of 3'-terminal regions, nucleotide sequences, and phylogenetic comparisons. J. Gen. Virol. 71:1451-1460.

36. Quemada, H. D., Gonsalves, D., and Slightom, J. L. 1991. Expression of coat protein gene from cucumber mosaic virus strain $\mathrm{C}$ in tobacco: Protection against infections by CMV strains transmitted mechanically or by aphids. Phytopathology 81:794-802.

37. Sanders, P. R., Sammons, B., Kaniewski, W., Haley, L., Layton, J., LaVallee, B. J., Delannay, X., and Tumer, N. E. 1992. Field resistance of transgenic tomatoes expressing the tobacco mosaic virus or tomato mosaic virus coat protein genes. Phytopathology 82:683-690.

38. Shrizadegan, M., Christie, P., and Seemann, J. R. 1991. An efficient method for isolation of RNA from tissue cultured plant cells. Nucleic Acids Res. 19:6055.

39. Shukla, D. D., and Ward, C. W. 1989. Structure of potyvirus coat proteins and its application in the taxonomy of the potyvirus group. Adv. Virus Res. 36:273-314.

40. Shukla, D. D., Ward, C. W., and Brunt, A. A. 1994. Chapter 5: Coat protein structure and variation. Pages 124-136 in: The Potyviridae. CAB International, Wallingford, U.K.

41. Stark, D. M., and Beachy, R. N. 1989. Protection against potyvirus infection in transgenic plants: evidence for broad spectrum resistance. Bio/Technology 7:1257-1262.

42. Thomson, K. G., Dietzgen, R. G., Gibbs, A. J., Tang, Y. C., Liesack, W., Teakle, D. S., and Stackebrandt, E. 1995. Identification of zucchini yellow mosaic potyvirus by RT-PCR and analysis of sequence variability. J. Virol. Methods 55:83-96.

43. Verwoerd, T. C., Dekker, B. M. M., and Hoekema, A. 1989. A smallscale procedure for the rapid isolation of plant RNAs. Nucleic Acids Res. 17:2362.

44. Wilson, J. J., Polyak, S. J., Day, T. D., and Gretch, D. R. 1995. Characterization of simple and complex Hepatitis $C$ virus quasispecies by heteroduplex gel shift analysis: Correlation with nucleotide sequencing. J. Gen. Virol. 76:1763-1771.

45. Wisler, G. C., Purcifull, D. E., and Hiebert, E. 1995. Characterization of the $\mathrm{P} 1$ protein and coding region of the zucchini yellow mosaic virus. J. Gen. Virol. 76:37-45. 